\title{
Potential use of human hair shaft keratin peptide signatures to distinguish gender and ethnicity
}

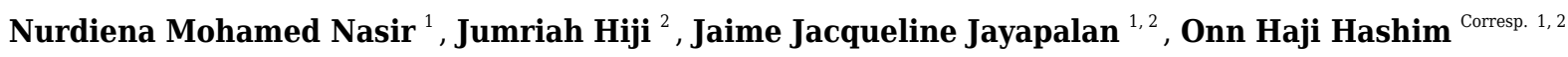 \\ ${ }^{1}$ Department of Molecular Medicine, Faculty of Medicine, University of Malaya, Kuala Lumpur, Wilayah Persekutuan, Malaysia \\ 2 University of Malaya Center for Proteomics Research, Faculty of Medicine, University of Malaya, Kuala Lumpur, Wilayah Persekutuan, Malaysia \\ Corresponding Author: Onn Haji Hashim \\ Email address: onnhashim@um.edu.my
}

Background. Most human hairs collected at old crime scenes do not contain nuclear DNA and are therefore of less value for forensic investigations. In the present study, hair shaft proteins were extracted from 40 healthy subjects between the ages of 21 to 40 years and profiled using gel electrophoresis-based proteomics to determine if they can be used to distinguish gender and ethnicity.

Methods. Extraction of the human hair shaft proteins was performed using a newly developed alkaline solubilisation method. The extracts were profiled by 2-dimensional electrophoresis and resolved protein spots were identified by mass spectrometry and queried against the human hair database. The study was then followed-up by immunoblotting of the identified hair shaft keratin of interest using commercially available antibodies.

Results. Separation of the human hair shaft proteins by 2-dimensional electrophoresis generated improved and highly resolved profiles. Comparing the hair shaft protein profiles of 10 female with 10 male subjects and their identification by mass spectrometry and query of the human hair database showed significant altered abundance of truncated/processed type-II keratin peptides K81 (2 spots), K83 (1 spot) and K86 (3 spots). The 2-dimensional electrophoresis profiling of 30 hair shaft samples taken from women of similar age range but from three distinctive ethnic subpopulations in Malaysia further showed significant altered abundance of one type-I and four type-II truncated/processed keratin peptides including K33b, K81, K83 and K86 (2 spots) between at least two of the ethnic groups. When a followedup immunoblotting experiment was performed to detect the relative expression of the K86 peptides using commercialised antibodies, similar trends of expression were obtained. The present data, when taken together, demonstrated the potential use of keratin peptide signatures of the human hair shaft to distinguish gender and ethnicity although this needs to be further substantiated in a larger scale study. 


\section{Potential use of human hair shaft keratin peptide}

\section{3 signatures to distinguish gender and ethnicity}

4

5

6 Nurdiena Mohamed Nasir ${ }^{1}$, Jumriah Hiji ${ }^{2}$, Jaime Jacqueline Jayapalan ${ }^{1,2}$ and Onn Haji

7 Hashim ${ }^{1,2, *}$

8

${ }^{1}$ Department of Molecular Medicine, ${ }^{2}$ University of Malaya Centre for Proteomics Research, Faculty of Medicine, University of Malaya, Kuala Lumpur, Malaysia

.

.

3

Corresponding Author:

Onn Haji Hashim*

Department of Molecular Medicine, Faculty of Medicine, University of Malaya, 50603, Kuala

Lumpur, Malaysia

Email address: onnhashim@um.edu.my

\section{8}


24 Abstract

Background. Most human hairs collected at old crime scenes do not contain nuclear DNA and are therefore of less value for forensic investigations. In the present study, hair shaft proteins were extracted from 40 healthy subjects between the ages of 21 to 40 years and profiled using gel electrophoresis-based proteomics to determine if they can be used to distinguish gender and ethnicity.

Methods. Extraction of the human hair shaft proteins was performed using a newly developed alkaline solubilisation method. The extracts were profiled by 2-dimensional electrophoresis and resolved protein spots were identified by mass spectrometry and queried against the human hair database. The study was then followed-up by immunoblotting of the identified hair shaft keratin of interest using commercially available antibodies.

Results. Separation of the human hair shaft proteins by 2-dimensional electrophoresis generated improved and highly resolved profiles. Comparing the hair shaft protein profiles of 10 female with 10 male subjects and their identification by mass spectrometry and query of the human hair database showed significant altered abundance of truncated/processed type-II keratin peptides K81 (2 spots), K83 (1 spot) and K86 (3 spots). The 2-dimensional electrophoresis profiling of 30 hair shaft samples taken from women of similar age range but from three distinctive ethnic subpopulations in Malaysia further showed significant altered abundance of one type-I and four type-II truncated/processed keratin peptides including K33b, K81, K83 and K86 (2 spots) between at least two of the ethnic groups. When a followed-up immunoblotting experiment was performed to detect the relative expression of the K86 peptides using commercialised antibodies, similar trends of expression were obtained. The present data, when taken together, demonstrated 
46 the potential use of keratin peptide signatures of the human hair shaft to distinguish gender and

47 ethnicity although this needs to be further substantiated in a larger scale study.

48 Introduction

The hair shaft is formed from epidermal keratinocytes undergoing a keratinization programme cell death termed cornification. This process involves degradation and destruction of the cell nucleus as well as the genetic material enclosed within it (Eckhart et al., 2013). As a result, nuclear DNA which may be used for genetic fingerprinting is usually not detected in the hair shaft (Bender \& Schneider, 2006). However, the application of next generation sequencing for the analysis of mitochondrial DNA, short tandem repeats, and single nucleotide polymorphisms has also demonstrated a great promise for forensically challenging samples (Shih et al., 2018).

On the other hand, the potential of distinguishing individual hair donors based on their hair shaft proteins has also been highlighted (Wu et al., 2017).

The complex interaction of these hair shaft proteins provides robust rigidity to the hair structure and makes it resistant to many environmental factors such as pollutants, weather, ultraviolet light or chemical treatments (Wolfram, 2003). Despite being well conserved, previous studies have shown that characterization of the hair shaft proteins can be challenging and difficult. This is mainly due to difficulties in solubilizing and extracting the proteins in solvents that are compatible with liquid chromatography or gel electrophoresis approaches (Sun et al., 2014; Kollipara \& Zahedi, 2013; Han et al., 2007; Smith \& Parry, 2007; Langbein \& Schweizer, 2005). While many attempts to improve the yield of proteins extracted from the human hair shaft have been reported, the quality of published 2-dimensional gel electrophoresis profiles is still far from being a useful method for forensic investigations and the process is also time-consuming and not practical to be applied in a large scale study (Takayama \& Ito, 2013; Barthelemy et al., 
2012; Thibaut et al., 2009; Plowman, 2007; Fuji, Nakamura et al., 2002). However, an alkaline solubilisation method which is capable of extracting substantially higher percentage of hair shaft proteins within only 2 hrs was recently developed (Wong et al., 2016). With this improved method and higher yield of hair shaft proteins, we analysed the hair material using 2-dimensional electrophoresis gel-based proteomics as well as immunodetection methods and compared the profiles to determine if they can be used to distinguish gender and/or ethnicity.

Methodology

\section{Subject recruitment}

A total of 40 healthy individuals of different genders and ethnicities but with the same age range (21 to 40 years) were recruited in the study in accordance to the ethical clearance granted by the Medical Ethics Committee of University of Malaya Medical Centre (MEC ID. NO: 20158-1577) (Institutional Review Board), which adheres to the Declaration of Helsinki. Informed written consent was acquired from all subjects prior to collection of their head hair samples. At least three strands of hair were collected from each subject and stored at $-20{ }^{\circ} \mathrm{C}$. In addition to visual inspection, information regarding subject's hair treatment habits and relevant past medical histories, if any, were collected using a questionnaire. Relevant phenotypic characteristics of the hair shaft including discoloration, whitening, bleaching, weathering and perming, if any, were recorded. Subjects with previous history of bacterial or fungal-borne skin diseases, inflammation or cancer and/or under treatment for such ailments and those with chemically-treated hair were excluded from the study. 


\section{Isolation of human hair shaft proteins}

92 Human hair shaft proteins were isolated using the alkaline solubilisation method in two stages as

93 previously described (Wong et al., 2016; Budowle \& Acton, 1981). Briefly, $5 \mathrm{mg}$ of hair samples

94 were sterilised with $90 \%$ ethanol, cut (1-4 mm) and incubated in $300 \mu$ l of lysis buffer at $90{ }^{\circ} \mathrm{C}$

95 for 30 mins in the first stage. The resulting supernatant fluids were isolated using a QIAquick

96 spin column (Qiagen, Hilden, Germany) and kept at $4^{\circ} \mathrm{C}$. The undissolved hair shaft fractions on

97 the other hand, were transferred into a fresh tube containing $300 \mu$ of lysis buffer with $0.1 \mathrm{M}$

$98 \mathrm{NaOH}$ and pulverised by magnetic stirring for 30 mins to increase the recovery of protein from

99 the second stage of extraction. The resulting solutions containing hair shaft protein extract were

100 centrifuged and the supernatant fluids were separated for subsequent precipitation of proteins

101 using $4^{\circ} \mathrm{C}$ acetone. Protein pellets were then solubilised in sample buffer and their

102 concentrations were assayed using the Bio-Rad protein assay (Bio-Rad, California, USA) in

103 accordance to the manufacturer's guidelines.

104

105

\section{2-dimensional electrophoresis and silver staining}

106 Solubilised hair shaft proteins $(100 \mu \mathrm{g})$ suspended in sample buffer were incubated in

rehydration buffer containing $7 \mathrm{M}$ urea, $2 \mathrm{M}$ thiourea, 4\% 3-[(3-cholamidopropyl)

108

dimethylammonio]-1-propanesulfonate hydrate, $2 \%$ immobilized $\mathrm{pH}$ gradient buffer $\mathrm{pH}$ 4-7,

109

$0.002 \% \mathrm{w} / \mathrm{w}$ orange $\mathrm{G}$ and $7 \mathrm{mg}$ of dithiothreitol (DTT) for $30 \mathrm{mins}$ at room temperature. The

110

sample mixtures were rehydrated with 13 cm DryStrip gel pH 4-7 (GE Healthcare, Uppsala,

111 Sweden) for $18 \mathrm{hrs}$ at room temperature in a closed environment. The rehydrated strips were

112 subjected to first dimensional gel electrophoresis separation using the Ettan IPGphor 3

113 Isoelectric Focusing System (GE Healthcare, Uppsala, Sweden) according to the following 
114 settings: (i) $500 \mathrm{~V}, 1 \mathrm{hr}$, step and hold; (ii) $1000 \mathrm{~V}, 1 \mathrm{hr}$, gradient; (iii) $8000 \mathrm{~V}, 2 \mathrm{hrs} 30$ mins,

115 gradient; (iv) $8000 \mathrm{~V}, 55$ mins, step and hold. The focused strip was initially incubated with

116 SDS equilibration buffer consisting of $6 \mathrm{M}$ urea, $75 \mathrm{mM}$ Tris-HCl, $\mathrm{pH} 8.8,30 \%$ (v/v) glycerol,

$1172 \%$ sodium dodecyl sulphate (SDS) and 1\%(w/v) DTT for 20 mins, followed by a second

118 equilibration in the same buffer but containing $4.5 \%(\mathrm{w} / \mathrm{v})$ iodoacetamide instead of DTT for

119 another 20 mins. Second dimension separation was performed on 8-15\% gradient

120 polyacrylamide gel using the SE 600 Ruby electrophoresis system (GE Healthcare, Uppsala,

121 Sweden). A concentration of $2.6 \%$ crosslinker (Bis) was used for the preparation of gels $(\% C)$.

122 Cathode running buffer containing $0.025 \mathrm{M}$ tris ( $\mathrm{pH} 8.3$ ), $0.192 \mathrm{M}$ glycine and 0.1\% SDS while,

123 the anode buffer containing $0.375 \mathrm{M}$ tris $(\mathrm{pH} 8.8)$ were used for the second dimensional gel

124 electrophoresis separation. Four gels were run according to the following program: (i) $50 \mathrm{~V}, 150$

$125 \mathrm{~mA}, 100 \mathrm{~W}$ for $1 \mathrm{hr}$; (ii) $600 \mathrm{~V}, 150 \mathrm{~mA}, 100 \mathrm{~W}$ until tracker dye reached bottom of the gel. The

126 electrophoresed gels were stained using silver nitrate (Yan et al., 2000). In this process, gels

127 were firstly fixed with $40 \%$ (v/v) ethanol and 10\% acetic acid for 30 mins, followed by

128 sensitization with $40 \%(\mathrm{v} / \mathrm{v})$ ethanol, $0.5 \mathrm{M}$ sodium acetate trihydrate and $8 \mathrm{mM}$ sodium

129 thiosulphate for 30 mins. Gels were then washed thrice, each time for 5 mins, and stained with

$13014.7 \mathrm{mM}$ silver nitrate solution. After washing two more times for $1 \mathrm{~min}$, gels were developed

131 with $0.24 \mathrm{M}$ sodium carbonate and 0.04\% (v/v) formaldehyde. Development of spots was

132 stopped with 40 mM EDTA solution and gels were finally kept in distilled water before being

133 scanned (see next section). Subsequent to the present study, a report on modification of this 2-

134 dimensional electrophoresis method, which generated further improved image resolution, was

135 published (Wong, Hayashi \& Hashim, 2019). 


\section{Data analysis}

138 Silver-stained 2-dimensional electrophoresis gels were scanned using ImageScanner III (GE

139 Healthcare, Uppsala, Sweden) and analysis of protein spot volume was performed using

140 ImageMaster Platinum 7.0 software (GE Healthcare, Uppsala, Sweden). Image analysis was

141 restricted to protein spot clusters that appeared consistently within each group of hair shaft

142 proteins. The levels of proteins in each sample were calculated as a percentage of volume

143 contribution $(\% \mathrm{vol})$ in which the volume of contribution refers to the volume percentage of a

144 protein taken against the total spot volume of all the proteins, in order to eliminate the possible

145 variations due to staining and/or protein loading. Automatic spot detection was performed with

146 default parameters setting (cut-off parameters were Smooth-2; Saliency-

147 1; Min area-5), whereas spot editing and removal of artefacts were done manually.

148 Data were analysed using the Statistical Package for Social Sciences (SPSS) version 25.0

149 (IBM Corporation, New York, USA). Shapiro-Wilk test of normality was used to assess the 150 distribution of the datasets. Parametric Student's t-test and ANOVA was used to analyse and

151 identify significant changes in expression between two population means (gender) and several

152 population groups (ethnicities), respectively, when the normality assumption was met $(p>0.05)$.

153 Following ANOVA, a pairwise comparison procedure was performed to test all possible

154 pairwise differences of the means using either Tukey HSD when equal variances was assumed

155 or, Dunnett's T3, if otherwise. On the other hand, non-parametric Mann-Whitney U and

156 Kruskal-Wallis tests with rank-based post-hoc test was used as their respective counterparts

157 when the assumption for normality was violated $(p<0.05)$. All values were presented as mean \pm

$15895 \%$ confidence interval, unless otherwise stated. A $p$ value of less than 0.05 and fold change of

159 more than 1.5-fold was considered significant. 


\section{Mass spectrometry and database search}

162

163

164

165

166

167

168

169

170

171

172

173

174

175

176

177

178

179

180

181

182

Identification of proteins was performed as previously described with minor modifications (Seriramalu et al., 2010). Briefly, protein spots of interests were carefully cut out from 2dimensional electrophoresis gels and kept in high-purity water at $-20^{\circ} \mathrm{C}$. Gel plugs were first destained using $15 \mathrm{mM}$ potassium ferricyanide (III) and $50 \mathrm{mM}$ sodium thiosulphate for $15 \mathrm{mins}$ at room temperature. The destaining procedure was repeated until the gel plugs became clear and transparent. The proteins in gel plugs were then reduced and alkylated using $10 \mathrm{mM}$ DTT and $55 \mathrm{mM}$ iodoacetamide both in $100 \mathrm{mM}$ ammonium bicarbonate. They were then washed thrice with $50 \%$ acetonitrile in $100 \mathrm{mM}$ ammonium bicarbonate, dehydrated with $100 \%$ acetonitrile and dried using vacuum centrifugation. The dried gels were treated with trypsin (6 $\mu \mathrm{g} / \mathrm{mL}$ in $50 \mathrm{mM}$ ammonium bicarbonate) for $18 \mathrm{hrs}$ at $37^{\circ} \mathrm{C}$. The resulting peptides were then dried, reconstituted in formic acid (0.1\%) and desalted using ZipTip with C18 resin (Millipore, Massachusetts, USA). The desalted and concentrated peptides were mixed with equal volume of a-cyano-4-hydroxycinnamic acid (6 mg/ml), before being spotted onto the OptiToF 384-well insert $(0.7 \mu \mathrm{l})$ of the 5800 MALDI ToF/ToF analyser (SCIEX, Framingham, USA).

The proteins were identified using MASCOT search engine (Perkins et al., 1999) and the resulting mass spectral data were thoroughly queried against the human hair entries in the Uniprot database (last update: January 17, 2019, containing 1329 sequences). The following parameters were set: enzyme: trypsin; maximum missed cleavages: 1; fixed modification: carbamidomethylation of cysteine; variable modification oxidation of methionine; precursor ion mass tolerance: $100 \mathrm{ppm}$; fragment ion mass tolerance: $0.2 \mathrm{Da}$. An individual ion score of more than 17 indicates extensive homology or identity $(p<0.05)$. 
184 Verification of altered protein abundance using immunoblotting

185 Immunoblotting was performed on pooled hair shaft protein samples of each groups of subjects, 186 to verify the altered abundance of proteins observed in the 2-dimensional electrophoresis

187 analysis. A total of $30 \mu \mathrm{g}$ of proteins for each pooled sample, determined using Bio-Rad protein 188 assay (Bio-Rad, California, USA), was separated on 12.5\% SDS polyacrylamide gel and

189

190

191

192 193 transferred onto PVDF membranes $(0.2 \mu \mathrm{m}$, PALL Life Sciences, Port-Washington, USA) using a Mini Trans-Blot ${ }^{\circledR}$ Electrophoretic Transfer Cell (Bio-Rad, Hercules, USA) for $1 \mathrm{~h}$ at $100 \mathrm{~V}$. Membranes were stained for total protein using MemCode ${ }^{\mathrm{TM}}$ Reversible Protein Stain Kit (Thermo Fisher Scientific, Waltham, USA), dried and scanned to be used as a loading control. After removal of Mem-Code ${ }^{\mathrm{TM}}$ staining, the membranes were blocked with 5\% skim milk in $1 \times$ TBST (25 mM Tris, $500 \mathrm{mM} \mathrm{NaCl}, 0.05 \%$ Tween, $\mathrm{pH}$ 7.5) for $30 \mathrm{mins}$, washed thrice, 5 mins with $1 \times$ TBST, and incubated with anti-KRT86 antibody (ab192754) (Abcam, Cambridge, UK) overnight at $4{ }^{\circ} \mathrm{C}$. After washing with $1 \times$ TBST thrice for 5 mins each wash, the membranes were incubated for $1 \mathrm{~h}$ with horseradish peroxidase conjugated goat anti-guinea pig IgG H\&L antibody (ab6908) (Abcam, Cambridge, UK). The membranes were washed again thrice, 5 mins with $1 \times$ TBST and developed either using 3, 3'-diaminobenzidine chromogen solutions (Thermo Fisher Scientific, Waltham, USA) containing 0.02\% hydrogen peroxide or WesternBright Sirius enhanced chemiluminescence system (Advansta, California, USA). MemCode ${ }^{\mathrm{TM}}$ signal and protein band intensities were obtained using the ImageJ Software (NIH, Bethesda, USA). 


\section{Hair shaft protein profiling - distinguishing genders and ethnicities}

206 The extraction yields of protein (\%) using the alkaline solubilisation method as previously

207 described by Wong et al. (2016) were generally higher compared to the methods of Lee et al.

208 (2006) and Shindai (Fujii \& Daguang, 2008). When alkaline solubilisation protein extraction

209 method was applied to $5 \mathrm{mg}$ of hair strands from 40 different individuals (30 females and 10

210 males), an average extraction yield of $63.56 \pm 6.59($ mean \pm SD) was obtained.

When the human hair shaft protein extracts from female and male subjects of the Malay

ethnic group were separated by 2-dimensional electrophoresis and subjected to silver staining, similar profiles were obtained (Fig. 1, panels A and B). The gel profiles were then subjected to ImageMaster 2D Platinum Software and statistical analyses (see section: Data analysis).

Abundance of 6 hair shaft protein spots was found to be significantly higher in female compared

to male subjects (Fig. 2). Spot 3 showed the highest mean percentage of volume contribution for females compared to males. The highest fold change difference was observed in spot 6 (Fig. 2). were significantly different in at least one ethnic group compared to the others (Fig. 3). Among demonstrated the highest fold change differences between Indian $(0.244 \pm 0.028)$ and Chinese $(0.038 \pm 0.079)$ subjects, as well as between Malay $(0.147 \pm 0.042)$ and Chinese $(0.038 \pm 0.027)$ the highest mean percentage of volume contribution for spots 7,9 and 11 compared to other 
227 showed the highest mean percentage of volume contribution in spot 10 and lowest values for

228 spots 9 and 11. In the Malay female subjects, spot 8 had the highest mean percentage of volume 229 contribution, while spot 7 was the least intense.

\section{Identification of hair shaft proteins by MALDI-ToF/ToF}

232

233

234

235

236

237

238

239

240

241

242

243

244

245

246

247

The hair shaft protein spots of significant altered abundance between subjects of different genders and ethnicities were identified using MALDI-ToF/ToF analysis and search of the human hair database (Table 1). Analysis of the 11 hair shaft proteins of interest (Fig. l) identified five different types of keratins, including (1) type II cuticular Hb6 (K86) for spots 3, 4, 5, 7 and 8, (2) type II cuticular $\mathrm{Hb} 3$ (K83) for spot 9, (3) type II cuticular $\mathrm{Hb} 1$ (K81) for spots 2, 6 and 10, (4) type II cuticular Hb5 (K85) for spot 1 and (5) type I cuticular Ha3-II (K33B) for spot 11. While the hair shaft of subjects of different genders demonstrated significant altered levels of K81, K85 and $\mathrm{K} 86$, those from different ethnicities showed significant different abundance of $\mathrm{K} 33 \mathrm{~B}, \mathrm{~K} 81$, K83 and K86.

\section{Verification of K86 abundance}

In this study, K86 was selected for verification of its abundances in the hair shaft of the subjects using immunoblotting method in view of its highest altered frequency as well as availability of commercialised antibodies against the protein. However, since the anti-K86 used is known to specifically recognise amino acids 446-469 of the keratin peptide, one of its peptide spots (spot 8), with amino acid sequences not in the region recognised by the antisera (Supplemental Table 
248 1), was not included in the analysis. Figure 4 demonstrates the representative images generated

249 from the immunoblotting experiments. The results obtained for K86 spots $(3,4,5$ and 7)

250 appeared to corroborate the findings previously obtained via two-dimensional gel electrophoresis

251 separation. K86 bands equivalent to the molecular weights of spots 3, 4 and 5 (spots 4 and 5

252 share similar molecular weight) appeared intensely stained in the female Malay subjects, relative

253 to the male counterparts, while the female Indian subjects demonstrated more intense K86 bands

254 compared to the female Malay and Chinese subjects. When analysed by densitometry, the

255 intensity ratios for female Malay:male Malay bands for spots 3-, 4- and 5-equivalent K86 bands

256 were $<1.5$-fold different, but significant $(p<0.05)$. On the other hand, the intensity ratios for

257 the K86 spot 7-equivalent band for female Malay versus Indian subjects showed $>1.5$-fold

258 difference $(\mathrm{FC}=1.62, p=0.008)$. The levels of spot 7-equivalent bands seemed comparable

259 between the female Malay and Chinese $(p>0.05)$ subjects.

261 Discussion

262 Protein profiling of the human hair shaft have shown promising avenue for providing definitive 263 identification in aid of forensic investigations ( $W u$ et al., 2017). Formed via cornification of

264 keratinocytes, the hair shaft mainly contains 17 different types of keratins, (i.e. K31-40 (including 265 K33a and K33b) and K81-86) (Moll, Divo \& Langbein, 2008), which are poorly analysed mainly

266 because of their limited solubility and extraction yield. In the present study, we have adopted a 267 newly developed protocol that enhanced the extraction yield of proteins from the human hair shaft 268 (Wong et al., 2016) and reanalysed the material. The gel profiles that were generated showed 269 reasonably improved resolution of the separated hair shaft proteins compared to those that were 
270 earlier reported (Barthelemy et al., 2012; Thibaut et al., 2009; Nakamura et al., 2002).

271 Identification of these proteins by mass spectrometry and search of the human hair protein database

272 showed that they comprised the different types of keratins, the cysteine-rich helicoidal proteins

273 that protect the hair because of their insolubility and impermeability.

274 In view of its reproducibility, the profiling of the human hair shaft proteins was further

275 utilised in a pilot study to determine if the developed profiles could be used to distinguish gender

276 of individuals. Our analysis of 20 hair shaft samples from healthy individuals between the age of

27721 to 40 years demonstrated significant higher abundance of six different type-II keratin spots,

278 including two K81, one $\mathrm{K} 85$ and three $\mathrm{K} 86$, in the women subjects compared to men. These

279 different types of keratins are known to be restricted to the hair shaft and not present in the follicle

280 (Moll, Divo \& Langbein, 2008). However, all these spots of altered abundance appeared to be

281 truncated or processed keratin products as they were resolved within the molecular weight regions

282 lower than their putative primary translated precursor polypeptides (Table 1). The influence or

283 effects of processing of proteins in this material remains to be elucidated in future investigations.

Similar marked shifts in molecular weights and isoelectric point $(\mathrm{p} I)$ values of the hair shaft

proteins that were separated by 2-dimensional electrophoresis, which may be due to deamidation,

post-translational modifications, or processing at the RNA level as sequence variants (Person et al., 2006), have been previously reported (Barthelemy et al., 2012). Whether this was an effect of the strong alkali used at $90^{\circ} \mathrm{C}$ in the hair shaft protein extraction, or that the proteins were further translation or during cornification, remains to be investigated. 
range but from three distinctive Malaysian ethnic subpopulations further showed significant altered abundance of one type-I (K33b) and four type-II (K81, K83 and two K86) keratins between the ethnic groups that were analysed. Like the earlier detected keratins, the type-I K33b and all the type-II keratins detected are also known to be localised exclusively in the hair shaft (Moll, Divo \& Langbein, 2008). Based on the resolved experimental molecular weights, all the five spots of altered abundance also appeared to be truncated or processed keratins. In addition, the K81 and K86 spots that were also detected in this analysis were different from their counterparts that were detected in the earlier gender analysis as they showed distinctive experimental molecular weight and $\mathrm{p} I$ values.

The results of the latter study also demonstrated that the Indian ethnic group to be most distinctive as they showed four abundantly different keratins (K33B, K81, K83 and K86 (spot 7)) compared to the Chinese and three keratins that were differently altered (K33B and two K86 (spots 7 and 8)) compared to the Malays. On the other hand, the Chinese and Malay ethnic groups only appeared to be distinctive in the abundance of K33B (3.87-fold of difference) and their levels of the type-I keratin were both significantly different compared to the Indians. These results are generally comparable with the genetic data that were earlier reported. In a study using multidimensional scale analysis on the population genetic structure of the different ethnic groups in Peninsular Malaysia, Hatin et al. (2011) had previously reported that the Malay and Chinese populations were clustered together while the Indians were further apart. substantiated the abundances of the K86 truncated peptides in the hair shaft of subjects previously 313 obtained via two dimensional gel separation method, with little variation in the levels of 
314 significance and/or intensity ratios (FC). The intensity of spots 3-, 4-, 5- and 7-equivalent K86 315 peptide bands appeared to corroborate the findings previously obtained via two-dimensional gel

316 electrophoresis separation. Together, these data further emphasise the potential of the keratin

317 peptide markers for distinguishing gender and ethnicity, and show promises for future forensic 318 applications.

\section{Conclusion}

321 When taken together, the human hair keratin profiling that was conducted in this pilot study 322 provided a potential method that can be used to distinguish gender and ethnicity of individuals 323 based on their hair shaft samples. However, a larger scale analysis of the hair shaft proteins using 324 antibodies that are specific to the different types of keratins that were highlighted in the present 325 study would be needed to increase the robustness of the results. This large scale study could 326 eventually lead to the development of a searchable database as well as signature keratin biomarkers 327 that could facilitate determination of one's gender and ethnicity based on their hair shaft keratin 328 profiles. Nonetheless, several other factors such as the effects of chemical exposure as well as confirmation of the accuracy of the results.

\section{References}

Barthélemy NR, Bednarczyk A, Schaeffer-Reiss C, Jullien D, Van Dorsselaer A, and Cavusoglu

N. 2012. Proteomic tools for the investigation of human hair structural proteins and evidence 
of weakness sites on hair keratin coil segments. Analytical Biochemistry 421:43-55. DOI: 10.1016/j.ab.2011.10.011

Bender K, and Schneider PM. 2006. Validation and casework testing of the BioPlex-11 for STR typing of telogen hair roots. Forensic Science International 161:52-59. DOI: 10.1016/j.forsciint.2005.10.024

Budowle B, and Acton RT. 1981. A technique for the detection of variable electrophoretic patterns of hair proteins. Electrophoresis 2:333-334. DOI:10.1002/elps.1150020516

Eckhart L, Lippens S, Tschachler E, and Declercq W. 2013. Cell death by cornification. Biochimica et Biophysica Acta (BBA)-Molecular Cell Research 1833:3471-3480. DOI: 10.1016/j.bbamcr.2013.06.010

Fujii T, Takayama S, and Ito Y. 2013. A novel purification procedure for keratin-associated proteins and keratin from human hair. Journal of Biological Macromolecules 13.

Fujii T, and Daguang, L. 2008. Preparation and properties of protein films and particles from chicken feather. Journal of Biological Macromolecules 8:48-55.

Han MO, Chun JA, Lee WH, Lee JW, and Chung CH. 2007. A simple improved method for protein extraction from human head hairs. Journal of Cosmetic Science 58:527-534.

Hatin WI, Zahri M-K, Xu S, Jin L, Tan S-G, Rizman-Idid M, Zilfalil BA, and Consortium HP-AS. 2011. Population genetic structure of Peninsular Malaysia Malay sub-ethnic groups. PloS One 6:e18312. DOI: 10.1371/journal.pone.0018312

Kollipara L, and Zahedi RP. 2013. Protein carbamylation: In vivo modification or in vitro artefact? Proteomics 13:941-944. DOI: 10.1002/pmic.201200452

Langbein L, and Schweizer J. 2005. Keratins of the human hair follicle. International Review of Cytology 243:1-78. DOI: 10.1016/S0074-7696(05)43001-6 
358 Lee YJ, Rice RH, and Lee YM. 2006. Proteome analysis of human hair shaft: From protein

359 identification to posttranslational modification. Molecular \& Cellular Proteomics 5:789800. DOI: $10.1074 / \mathrm{mcp} . M 500278-\mathrm{MCP} 200$

361

362

363

364

365

366

367

368

369

370

371

372

373

374

375

376

377

378

379

McNevin D, Wilson-Wilde L, Robertson J, Kyd J, and Lennard C. 2005. Short tandem repeat (STR) genotyping of keratinised hair - Part 1. Review of current status and knowledge gaps. Forensic Science International 153:237-246. DOI: 10.1016/j.forsciint.2005.05. 006

Moll R, Divo M, and Langbein L. 2008. The human keratins: biology and pathology. Histochemistry and Cell Biology 129:705. DOI: 10.1007/s00418-008-0435-6

Nakamura A, Arimoto M, Takeuchi K, and Fujii T. 2002. A rapid extraction procedure of human hair proteins and identification of phosphorylated species. Biological and Pharmaceutical Bulletin 25:569-572. DOI: 10.1248/Bpb.25.569

Perkins DN, Pappin DJ, Creasy DM, and Cottrell JS. 1999. Probability-based protein identification by searching sequence databases using mass spectrometry data. Electrophoresis 20:35513567. DOI: 10.1002/(SICI)1522-2683(19991201)20:18<3551::AID-ELPS3551>3.0.CO;22

Person MD, Shen J, Traner A, Hensley SC, Lo H-H, Abbruzzese JL, and Li D. 2006. Protein fragment domains identified using 2D gel electrophoresis/MALDI-TOF. Journal of Biomolecular Techniques 17:145.

Pfeiffer H, Brinkmann B, Huhne J, Rolf B, Morris AA, Steighner R, Holland MM, and Forster P. 1999. Expanding the forensic German mitochondrial DNA control region database: genetic diversity as a function of sample size and microgeography. International Journal of Legal Medicine 112:291-298. DOI 10.1007/s004140050252 
380 Plowman JE. 2007. The proteomics of keratin proteins. Journal of Chromatography B 849:181-

381 189. DOI: $10.1016 /$ j.jchromb.2006.07.055

382 Seriramalu R, Pang WW, Jayapalan JJ, Mohamed E, Abdul-Rahman PS, Bustam AZ, Khoo AS, 383 and Hashim OH. 2010. Application of champedak mannose-binding lectin in the 384 glycoproteomic profiling of serum samples unmasks reduced expression of alpha-2 macroglobulin and complement factor $\mathrm{B}$ in patients with nasopharyngeal carcinoma. Electrophoresis 31:2388-2395. DOI: 10.1002/elps.201000164

Shih S, Bose N, Gonçalves A, Erlich H, and Calloway C. 2018. Applications of probe capture enrichment next generation sequencing for whole mitochondrial genome and 426 nuclear SNPs for forensically challenging samples. Genes 9:49. DOI:10.3390/genes9010049

Smith TA, and Parry DAD. 2007. Sequence analyses of Type I and Type II chains in human hair and epithelial keratin intermediate filaments: Promiscuous obligate heterodimers, Type II template for molecule formation and a rationale for heterodirner formation. Journal of Structural Biology 158:344-357. DOI: 10.1016/j.jsb.2006.12.002

Sun SS, Zhou JY, Yang WM, and Zhang H. 2014. Inhibition of protein carbamylation in urea solution using ammonium-containing buffers. Analytical Biochemistry 446:76-81. DOI: 10.1016/j.ab.2013.10.024

Thibaut S, Cavusoglu N, de Becker E, Zerbib F, Bednarczyk A, Schaeffer C, van Dorsselaer A, and Bernard BA. 2009. Transglutaminase-3 Enzyme: A Putative Actor in Human Hair Shaft Scaffolding? Journal of Investigative Dermatology 129:449-459. DOI: $10.1038 /$ jid.2008.231

Wong SY, Hashim OH, and Hayashi N. 2019. Development of high-performance two-dimensional gel electrophoresis for human hair shaft proteome. PloS One 14:e0213947. 
403 Wong SY, Lee CC, Ashrafzadeh A, Junit SM, Abrahim N, and Hashim OH. 2016. A high-yield 404 two-hour protocol for extraction of human hair shaft proteins. PloS One 11:e0164993. DOI: 10.1371/journal.pone.0164993

406

407

408

409

410

411

412

Wu P-W, Mason KE, Durbin-Johnson BP, Salemi M, Phinney BS, Rocke DM, Parker GJ and Rice RH. 2017. Proteomic analysis of hair shafts from monozygotic twins: Expression profiles and genetically variant peptides. Proteomics 17:1600462. DOI: 10.1002/pmic.201600462

Yan JX, Wait R, Berkelman T, Harry RA, Westbrook JA, Wheeler CH, and Dunn MJ. 2000. A modified silver staining protocol for visualization of proteins compatible with matrix-assisted laser desorption/ionization and electrospray ionization-mass spectrometry. Electrophoresis 21:3666-3672. 


\section{Figure 1}

Figure 1. Representative hair shaft protein profiles.

In panel A, circled are 11 protein spots that were significantly different in abundance between gender [male $(n=10)$ and female $(n=10)$ subjects of the same ethnicity (Malaysian Malay)] (spots 1-6) and three different ethnicities [Malaysian Malay $(n=10)$, Chinese $(n=10)$ and Indian ( $n=10)$ female subjects] (spots 7-11). Panels B, C and D demonstrate representative hair shaft protein profiles of male Malay, female Chinese and Indian subjects, respectively.

A

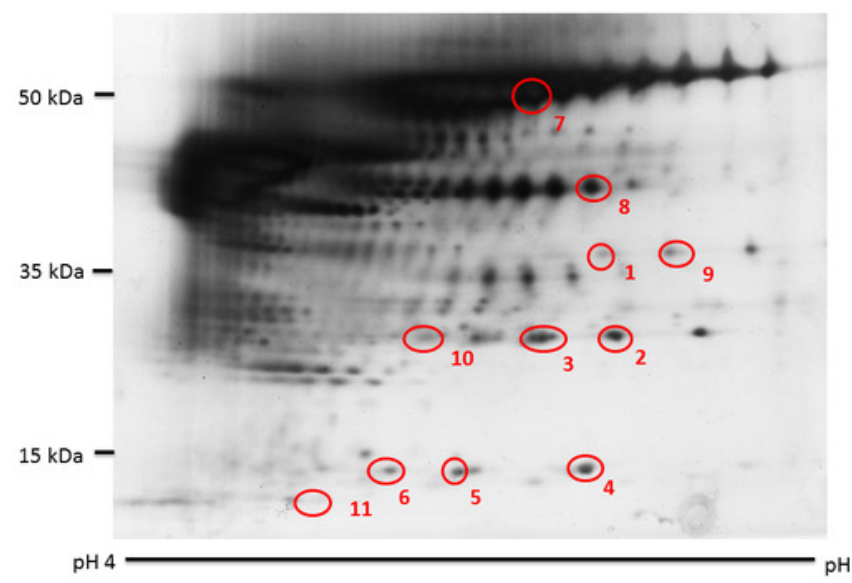

C

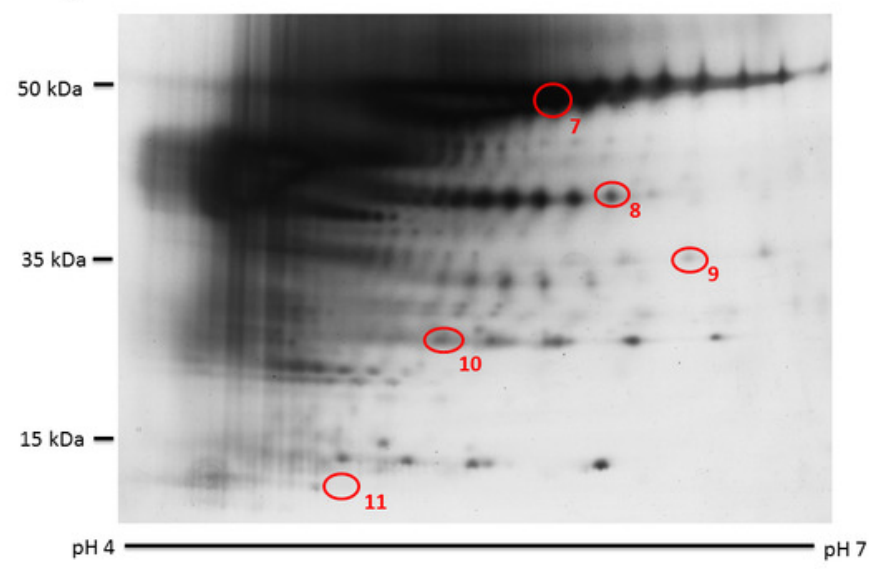

B

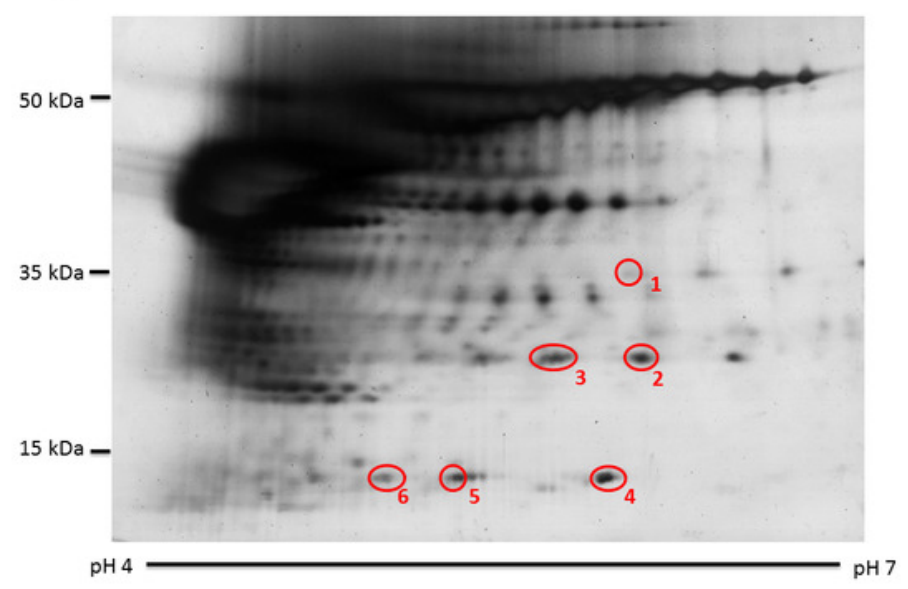

D

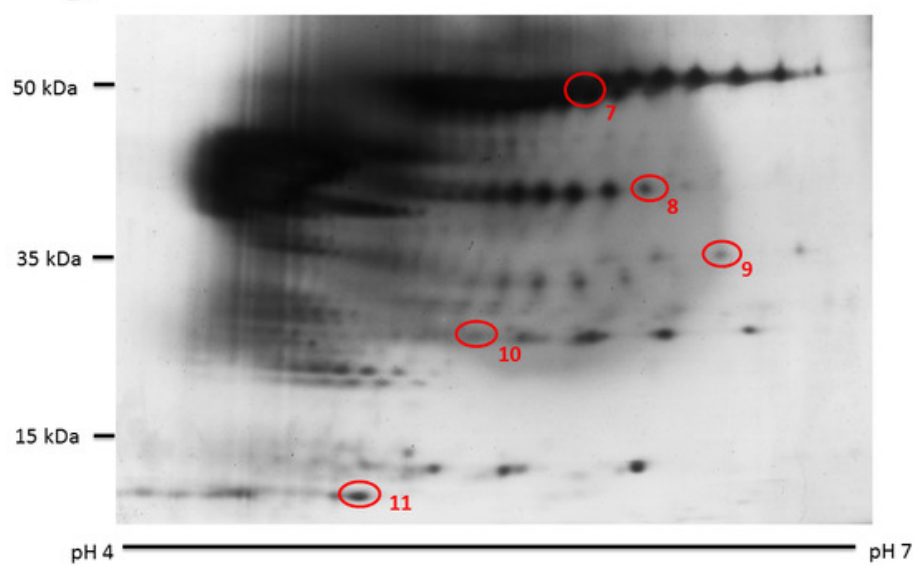




\section{Figure 2}

Figure 2. Volume contribution of 6 hair shaft protein spots that were significantly different between male and female subjects (Fig. 1).

Gel images were analysed by ImageMaster 2D Platinum Software (mean $\pm 95 \%$ confidence interval; $n=20$ ). Panels A - F demonstrate the 6 protein spots (K85, three protein species of K86 and two protein species of K81) that were significantly different in abundance between male and female subjects. FC is fold change between the mean values for males and females. Error bars represent 95\% confidence intervals.

A

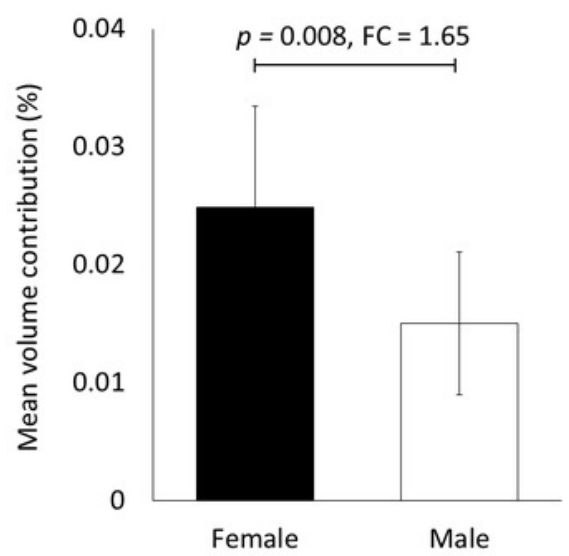

D

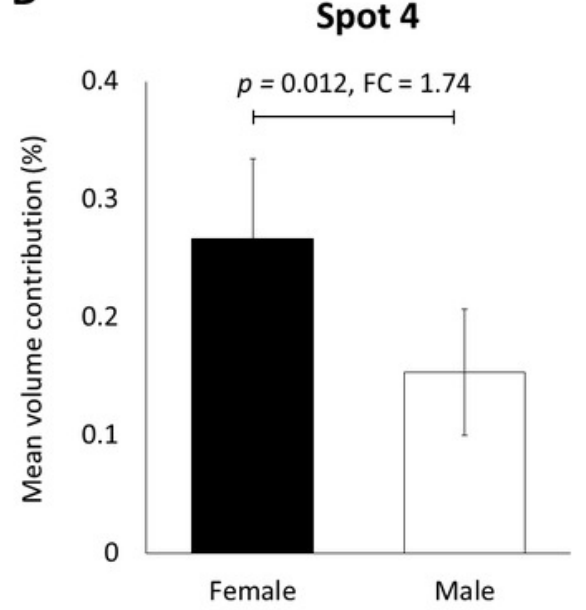

B

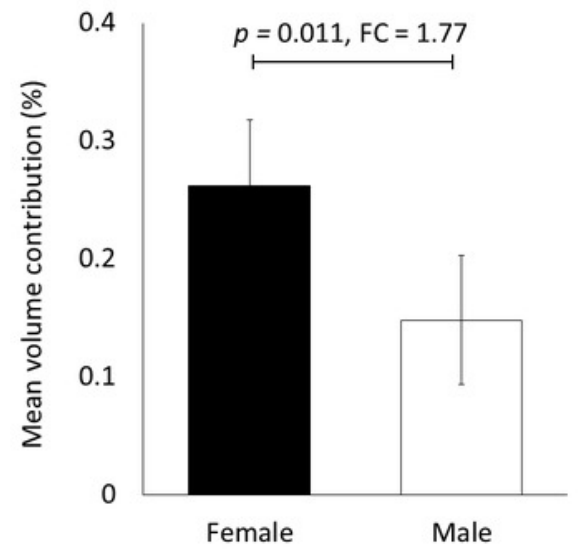

$\mathbf{E}$

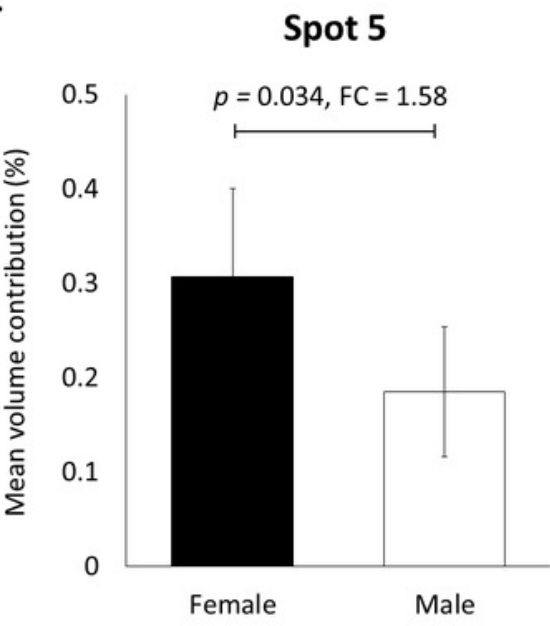

C

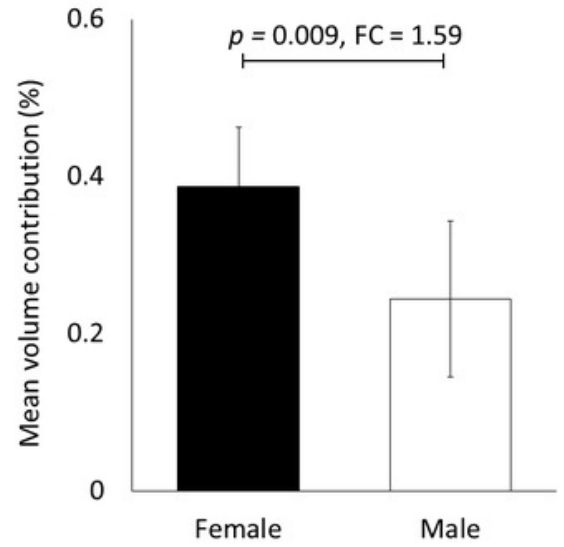

$\mathbf{F}$

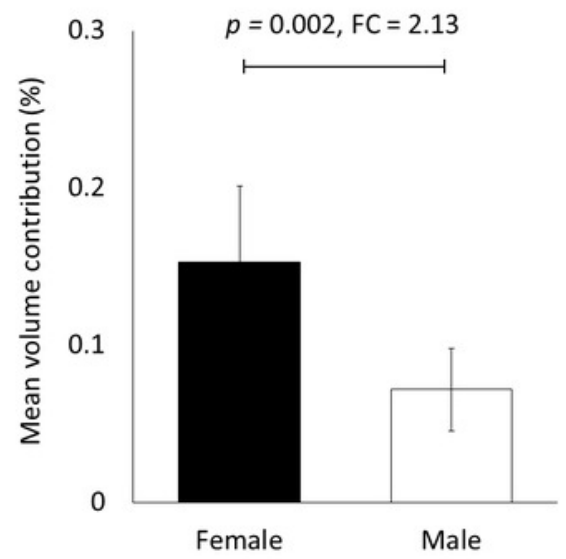




\section{Figure 3}

Figure 3. Volume contribution of hair shaft protein spots that were significantly different between the three different ethnicities.

The 5 protein spots (two protein species of $\mathrm{K} 86, \mathrm{~K} 83$, K81 and $\mathrm{K} 33 \mathrm{~B}$ corresponding to the spot numbers 7-11 shown in Fig. 1 - panels B - D, respectively) of significant altered abundance between Malay $(n=10)$, Chinese $(n=10)$ and Indian $(n=10)$ subjects as analysed by ImageMaster 2D Platinum Software of gel profiles (mean $\pm 95 \%$ confidence interval) were demonstrated (Panels A - E). FC is fold change between the mean values. Error bars represent $95 \%$ confidence intervals.

A

Spot 7

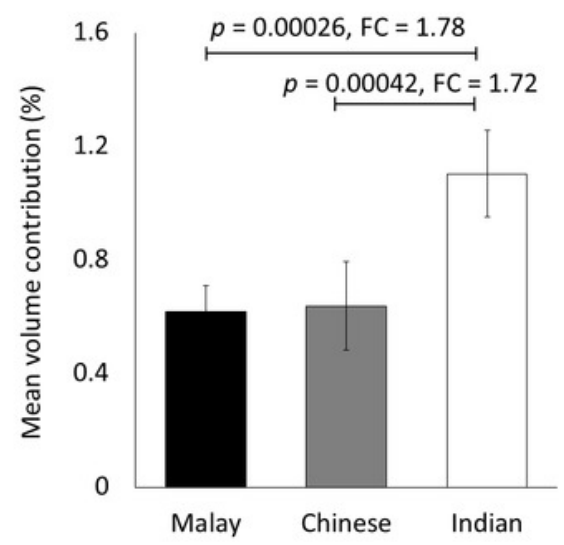

D

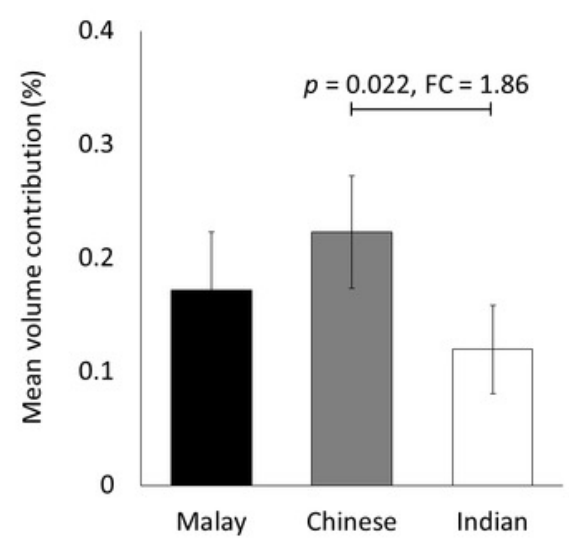

B

Spot 8

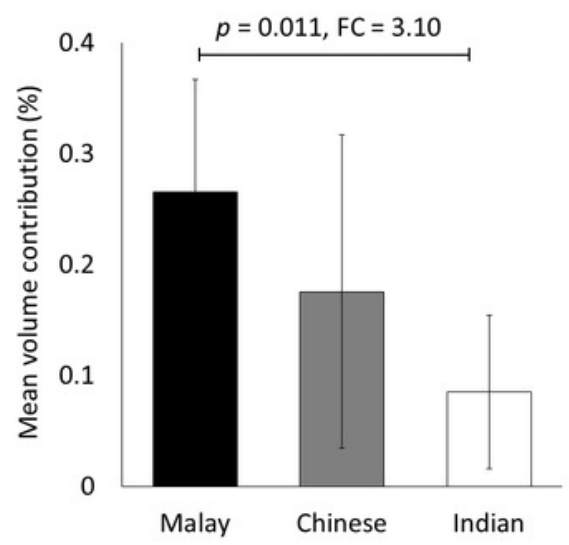

E

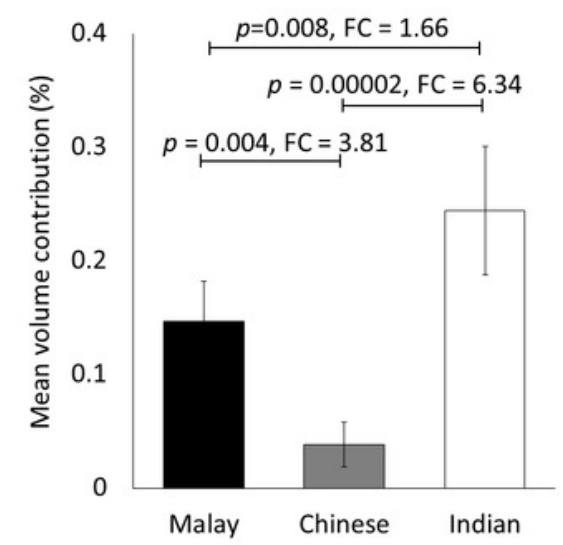

C

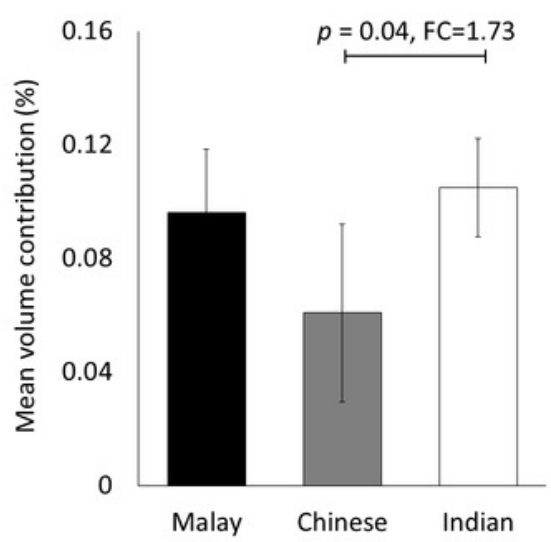




\section{Figure 4}

Figure 4. Immunoblotting of hair shaft K86.

Pooled hair shaft proteins were initially subjected to SDS-polyacrylamide gel electrophoresis and transferred electrophoretically onto PVDF membranes. Immunodetection was performed using polyclonal guinea pig antisera against K86, whilst peroxidase-conjugated goat antiguinea pig antibody was used as secondary antisera. The PVDF membranes was developed using WesternBright Sirius enhanced chemiluminescence system. Normalised intensity values are ratios of the relative intensities of the bands to their respective loading controls (intensities of total protein using MemCode ${ }^{\mathrm{TM}}$ Reversible Protein Stain Kit). Panels A, B and C demonstrate cropped images of bands while, panels $D, E \& F$ shows normalised intensities of the four K86 peptides (spots 3, 4, 5 and 7, respectively). Error bars represent 95\% confidence intervals. 
A

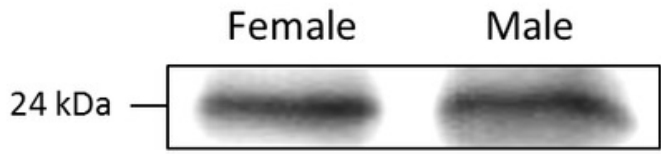

Spot 3

B

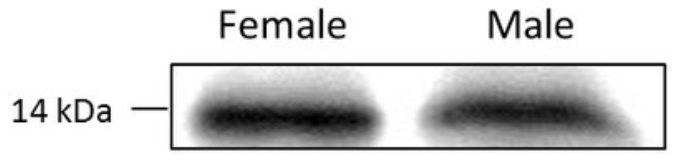

Spots 4 \& 5

C

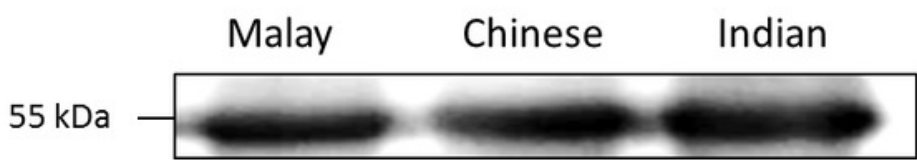

Spot 7
D Spot 3

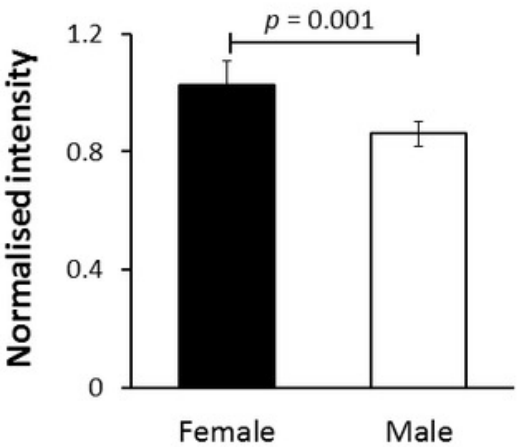

E
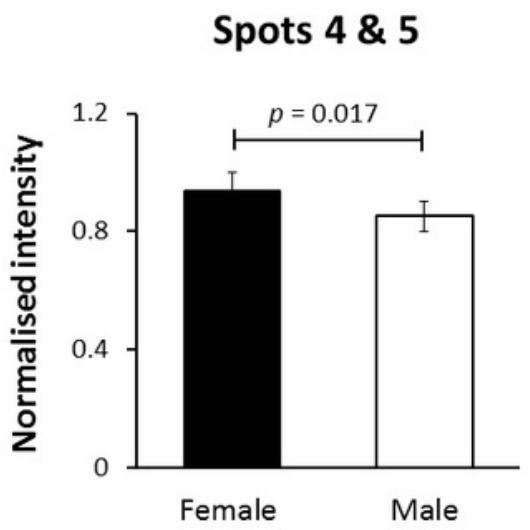

F

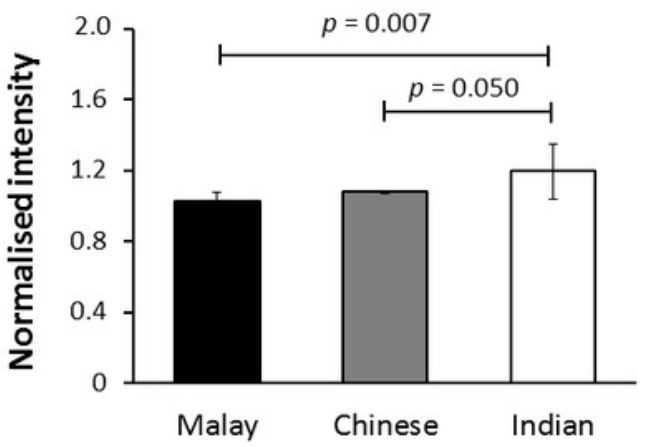




\section{Table $\mathbf{1}$ (on next page)}

Table 1. MS identification of 2-dimensional electrophoresis hair shaft protein gel spots of altered abundance.

Spots that were significantly different in abundance between subjects of distinct genders (spots 1-6) and ethnicities (spots 7-11) were excised from gels and subjected to in-gel trypsin digestion, MALDI-ToF/ToF analysis and human hair database query (Fig 1.). Experimental mass was calculated based on relative mobilities $\left(R_{f}\right)$ of the spots. cov - coverage; $\mathrm{pl}$ isoelectric point. 


\begin{tabular}{|c|c|c|c|c|c|c|c|c|c|c|}
\hline $\begin{array}{c}\text { Spot } \\
\text { number }\end{array}$ & $\begin{array}{c}\text { Accession } \\
\text { number }\end{array}$ & Protein name & Abbreviation & $\begin{array}{l}\text { Mascot } \\
\text { score }\end{array}$ & $\begin{array}{l}\text { Sequence cov } \\
(\%)\end{array}$ & $\begin{array}{l}\text { Distinct } \\
\text { peptides }\end{array}$ & $\begin{array}{l}\text { Theoretical } \\
\text { mass (Da) }\end{array}$ & $\begin{array}{c}\text { Experimental } \\
\text { mass (Da) }\end{array}$ & $\begin{array}{c}\text { Theoretical } \\
\text { pI }\end{array}$ & $\begin{array}{c}\text { Experimental } \\
\text { p } I\end{array}$ \\
\hline 1 & P78386 & $\begin{array}{c}\text { Keratin, type-II } \\
\text { cuticular Hb5 }\end{array}$ & K85 & 74 & 6 & 4 & 57,306 & 32,359 & 6.28 & 5.90 \\
\hline 2 & Q14533 & $\begin{array}{c}\text { Keratin, type-II } \\
\text { cuticular Hb1 }\end{array}$ & K81 & 51 & 3 & 2 & 56,832 & 24,547 & 5.40 & 6.00 \\
\hline 3 & O43790 & $\begin{array}{l}\text { Keratin, type-II } \\
\text { cuticular Hb6 }\end{array}$ & K86 & 106 & 10 & 4 & 55,120 & 24,547 & 5.56 & 5.70 \\
\hline 4 & O43790 & $\begin{array}{c}\text { Keratin, type-II } \\
\text { cuticular Hb6 }\end{array}$ & K86 & 105 & 15 & 5 & 55,120 & 13,803 & 5.56 & 5.70 \\
\hline 5 & O43790 & $\begin{array}{l}\text { Keratin, type-II } \\
\text { cuticular Hb6 }\end{array}$ & K86 & 49 & 7 & 3 & 55,120 & 13,803 & 5.56 & 5.30 \\
\hline 6 & Q14533 & $\begin{array}{c}\text { Keratin, type-II } \\
\text { cuticular Hb1 }\end{array}$ & K81 & 42 & 1 & 1 & 56,832 & 13,803 & 5.40 & 5.00 \\
\hline 7 & O43790 & $\begin{array}{c}\text { Keratin, type-II } \\
\text { cuticular Hb6 }\end{array}$ & K86 & 509 & 35 & 15 & 55,120 & 54,954 & 5.56 & 5.50 \\
\hline 8 & O43790 & $\begin{array}{c}\text { Keratin, type-II } \\
\text { cuticular Hb6 }\end{array}$ & K86 & 164 & 11 & 7 & 55,120 & 39,810 & 5.56 & 5.90 \\
\hline 9 & P78385 & $\begin{array}{l}\text { Keratin, type-II } \\
\text { cuticular Hb3 }\end{array}$ & K83 & 55 & 2 & 2 & 55,928 & 32,359 & 5.54 & 6.30 \\
\hline 10 & Q14533 & $\begin{array}{l}\text { Keratin, type-II } \\
\text { cuticular Hb1 }\end{array}$ & K81 & 51 & 3 & 2 & 56,832 & 24,547 & 5.40 & 5.20 \\
\hline 11 & Q14525 & $\begin{array}{l}\text { Keratin, type-I } \\
\text { cuticular Ha3-II }\end{array}$ & K33B & 18 & 2 & 1 & 47,338 & 11,749 & 4.81 & 4.80 \\
\hline
\end{tabular}

1 